\title{
Corneodermatoosseous syndrome
}

INSERM

\section{Source}

INSERM. (1999). Orphanet: an online rare disease and orphan drug data base.

Corneodermatoosseous syndrome. ORPHA:3194

A rare, genetic, ectodermal dysplasia syndrome characterized by corneal epithelial changes (ranging from roughening to nodular irregularities), diffuse palmoplantar hyperkertosis with thickened, erythematous, scaly lesions affecting the elbows, knees and knuckles, distal onycholysis, brachydactyly accompanied by a single transverse palmar crease, short stature, premature birth, and increased susceptibility to tooth decay. Ocular symptoms include photophobia, reduced night vision, burning and watery eyes, and varying visual acuity. There have been no further descriptions in the literature since 1984. 